\title{
2.2. Morphological Variability and Taxonomic Differentiation
}

\author{
Jan RACZYŃSKI
}

\subsubsection{Morphological Characteristics}

The genus Clethrionomys comprises small and medium voles characterized by many specific features, particularly as compared with the genus Microtus, which is rich in species numbers. These features include:

- closing of the molars root with age, and the development of roots (only C. rufocanus produces roots at an older age and the Japanese forms, C. rex and C. andersoni, produce roots only in the very oldest age groups),

- rounded loops of enamel on the wearing surface of molars,

- the palate in the form of flat lamina is ended by a distinct rim closer to anterior edges of the crown of $\mathrm{M}^{3}$ (Fig. 2.3),

- a delicate skull, rounded, with shortened facial part, without frontal crest (crista frontalis),

- relatively large ears, protruding from the fur,

- rusty-red coloration of the back in some species (C. rutilus, C. glareolus).

Particular species of the genus Clethrionomys vary slightly in size, in body-tail proportions, details of skull and dental morphology, and first of all in the coloration of the fur.

Clethrionomys glareolus (Schreber, 1780) - the bank vole, is characterized by medium body size: Head and body $80-129 \mathrm{~mm}$, tail $40-60 \mathrm{~mm}$ (about $50 \%$ of the body), hind foot $14-18 \mathrm{~mm}$, body weight ' $\mathrm{f}-20 \mathrm{~g}$, in summer sometimes more than $30 \mathrm{~g}$ (the size of animals from populations living in Poland is given in the next subsection).

The dentition of the bank vole is shown in Figure 2.4. It differs from the dentition of other Microtinae, and particularly from European forms of the genus Microtus, in many characters such as:

- gentle design of the enamel lines forming rounded loops in the front and hind parts of the tooth, and rounded triangles on both lateral edges (only in young individuals are these edges sharper),

- enamel loops of $\mathrm{M}_{2}$ form three joined fields of dentine due to a specific configuration of opposite triangles (in the genus Microtus these triangles are always separated),

- enamel triangles of $\mathrm{M}_{1}$ (denoted by numbers 2-3 and 4-5) form dentine fields clearly joined with each other,

- The last upper molar, $\mathrm{M}^{3}$, does not protrude much from the bony 


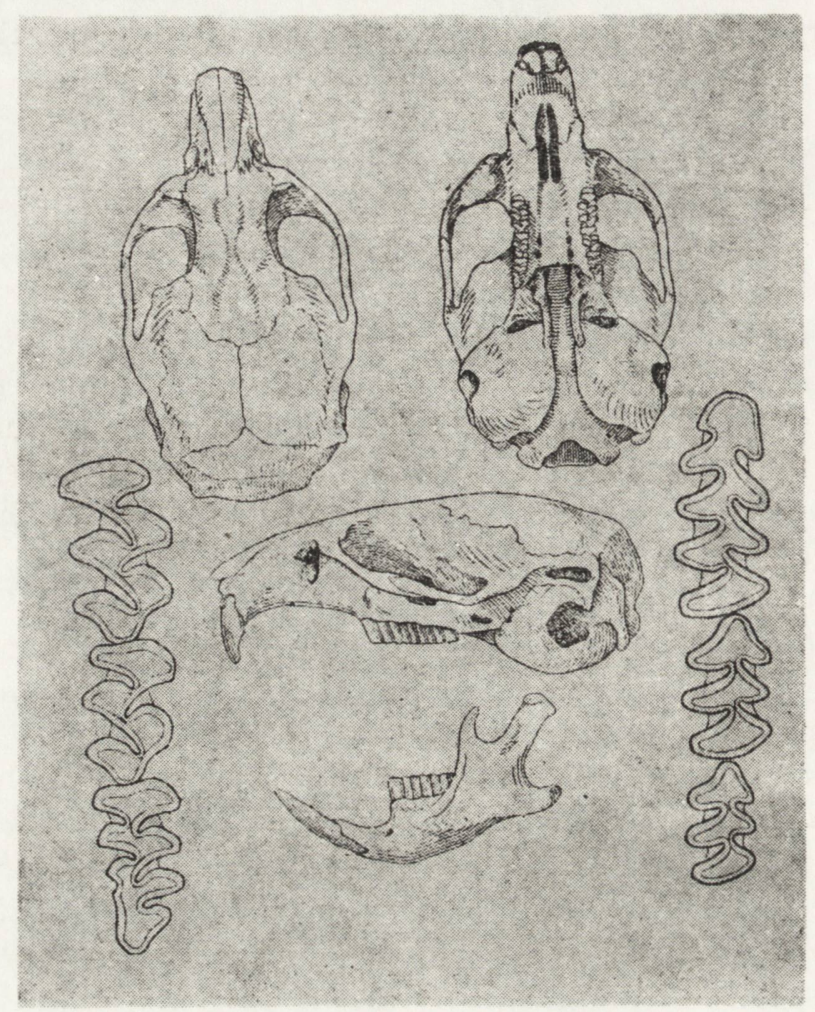

Fig. 2.3. A bank vole skull. The proportions between the cranial and visceral parts, and the hard palate margin are denoted (after Gromov and Polyakov, 1977).

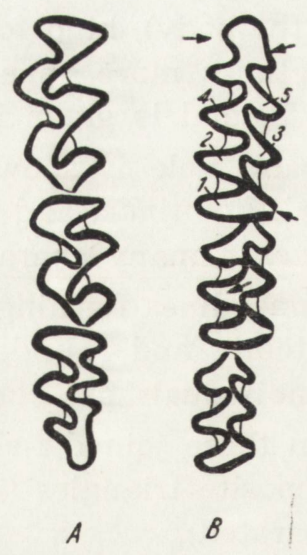

Fig. 2.4. An outline of the structure of wearing surface of molars in the bank vole. A - upper molar row, left side; B - lower molar row, right side (after Chaline et al., 1974). 
edge of the jaw, and it varies greatly in wearing surface structure (Fig. 2.5).

Bank vole fur is rusty-brown on the back, often with a reddish tint. Sides are paler, with a grey tint, belly light silvery grey, sometimes whitish with yellow tint. The zone separating the coloration of the back and belly is well demarcated. The tail is bicoloured, lighter beneath, crested with hair at the tip. The pelage of young individuals is generally more grey and with less contrasting shades. Moulting occurs in spring and autumn, typically from the back region towards the head.

The coloration of the bank vole fur varies relatively little over the wide range of this species. For example, voles from England, Germany, and France cannot be distinguished from each other on the base of their coloration (Corbet, 1964). On a vast geographical area from the Biało-

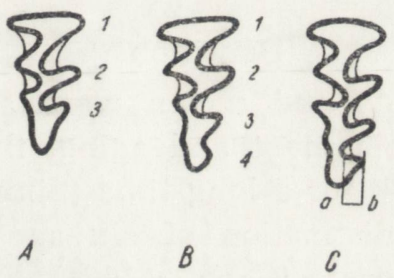

Fig. 2.5. Types of the structure of enamel loops of $\mathrm{M}^{3}$. Lingual corners are denoted by numbers $1-4$.

A - "simplex" type; B, C - "complex" types. Line a-b denotes the degree of the development of the fourth lingual corner (triangle) of enamel. The measurement of line $a-b$ provides a quantitative characteristic of this feature (after Corbet, 1963).

wieża Forest to Arkhangelsk and the Pechora basin, Rossolimo (1964) did not find any trends in coloration variability. Local forms differing in colour were described only in a few, usually isolated populations, (Corbet and Southern, 1977). Albinisms and melanism occur rare as they are due to genetic anomalies. Non-agouti forms are due to recessive alleles (eight at least) and they are phenotypically expressed in homozygotes. One case of an extreme non-agouti mutation (black colour of the fur) in the bank vole has been described from southern Poland by Bobek and Bartke (1967); other melanistic individuals are reported by Husson (1953) and Hanak (1957). One albinotic specimen from Germany was described by Reichstein and Kulicke (1958). Differences in coloration between lowland and mountain populations considered as taxonomic features often are not confirmed in larger series of material (Prychodko, 1951).

The number of chromosomes in the bank vole is relatively constant 
as compared with that in the genus Microtus. The karyotype of the nominative subspecies, C. glareolus glareolus, from Germany, Hungary, and different regions of Czechoslovakia is $2 \mathrm{~N}=56$ chromosomes, incloding 2 metacentric autosomes and a metacentric $\mathrm{Y}$ chromosome $(\mathrm{NFa}=56, \mathrm{NF}=58, \mathrm{Kral}, 1972)$. The karyotype of south-European subspecies, C. g. istericus and C. g. garganicus, has the same number of chromosomes $(2 \mathrm{~N}=56)$, and differs only by the acrocentric $\mathrm{Y}$ chromosome. The latter feature has been recorded in peripheral populations of Palaearctic species, and it is a suitable genetic marker in these populations (Voroncov et al., 1978). Chromosomally Palearctic C. glareolus and Nearctic C. gapperi are identical (Matthey, 1956), but this evidence is insufficient to suggest conspecifity of these forms.

\subsubsection{Morphological Variability}

\section{Dentition}

Growth of molar roots and crown wear are continuous processes related to postnatal development and aging, therefore they have been used for age determination for a long time (Zimmermann, 1937)*. Tooth morphology allows the distinction of six age classes illustrating the developmental stages of roots (Corbet, 1964). For this purpose, usually the roots of $\mathrm{M}_{1}$ (Prychodko, 1951; Wasilewski, 1952) or $\mathrm{M}^{2}$ (Koshkina, 1955; Tupikova et al., 1968) are used as they are easier to extract from the jaw. The problem of age homogeneity in particular classes of root length is related to the rate of root growth and crown wear which are species specific and often population specific. The most important is the different growth rate of animals in the spring and autumnal vole generations. In view of this fact, absolute values of monthly tooth increases under laboratory conditions (Mazák, 1963), or in the wild (Tupikova et al., 1968) used as the basis for estimating the absolute age of animals should be cautiously considered. Large differences in the growth rate of root length between the spring generation $(0.23 \mathrm{~mm} / \mathrm{month})$ and the autumnal generation $(0.16 \mathrm{~mm})$ are described by Zejda $(1961,1971)$, and the differences in growth between summer $(0.2 \mathrm{~mm})$ and winter $(0.1 \mathrm{~mm})$ by Claude (1970).

Another age-related feature in the development of molar roots was noticed by Hinton (1926). This is the disappearance of the alveolar capsules with age (Fig. 2.6). This is an arched swelling of processus alveolaris maxillae, visible within the temporal fovea (Prychodko, 1951; Koshkina, 1955). This morphological feature, easily seen on prepared

* Other ways of age determination from morphological features of the bank vole are described in section 6.2 . 
skulls, can facilitate the distinction between adult and young bank voles in some ecological investigations.

Variability in the structure of the grinding surface of $\mathrm{M}^{3}$ in the bank vole was noticed by Rörig \& Börner (1905) and classified in detail. For some species (e.g. Microtus arvalis) this feature was used to interprete population dynamics of this species in different areas, assuming that particular variants are of selective value (Stein, 1958), and considering them as taxonomic features of subspecies.

In the bank vole, two basic types of the $\mathrm{M}^{3}$ crown are described: 1) "Simplex", which is a shortened form with three triangles of enamel on the labial and lingual sides of the tooth; 2) "Complex", which is a developed form of the tooth with four lingual and four labial triangles.

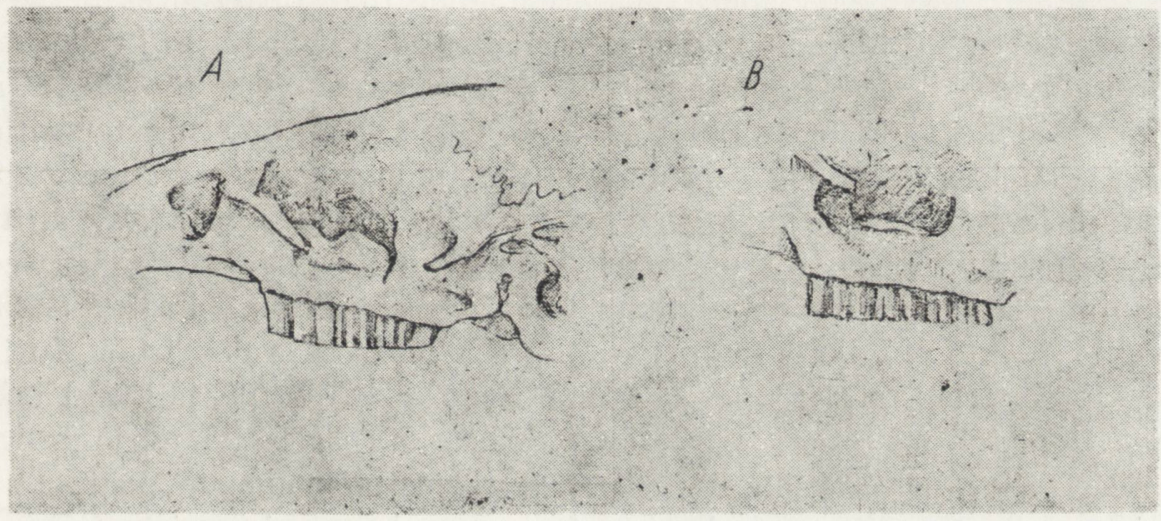

Fig. 2.6. The structure of the alveolar capsule, which is a convenient feature to visually estimate the age of bank voles from the skull material (Original).

A - young individual, strongly arched alveolar capsule, B - old individual with well-developed roots, the capsule flattened and reduced.

There are, however, many intermediate forms between these extremes (Prychodko, 1951), which indicate a complex character of inheritance of this feature (see Fig. 2.5). Bank vole populations living in England are characterized by a high proportion of the simplex form (Steven, 1955). Detailed studies have shown, however, that neighbouring populations can markedly differ in the proportion of the two forms, which reduces the taxonomic importance of this feature (Corbet, 1963). An additional limitation is due to the fact that it is difficult to classify these variants in older age classes because of tooth wear (Zejda, 1960).

Body and skull sizes

Among body measurements, only the length of hind foot and ear are fairly constant, thus of taxonomic value. The body length and weight can vary greatly, depending on geographic location and popula- 
tion variability. The intrapopulation source of variability is related to sexual activity of individual bank voles and to the age structure of the population. It also shows a clear seasonal aspect. This variability is discussed in detail by Kubik (1965). The relationship between the body weight and sexual activity is analysed by Zejda (1965).

According to Rossolimo (1964), the geographical variability of the skull is low over a large area from central Europe to the Pechora river in the east, and from Yugoslavia to Arkhangelsk. Some skull measurements, e.g. inter-orbital breadth or rostrum breadth do not vary. Variability in condylo-basal length is more distinct but it has no trend and is not large enough to indicate subspecific differentiation in the population. Instead, seasonal differences are clearcut: difference between the summer and winter specimens are higher than differences between geographically distant populations (Rossolimo, 1964). In relatively thoroughly studied populations of the British bank vole, the skull and body size tend to increase northwards (Corbet, 1964), a distinct position being occupied by isolated forms from small islands (see section 2.2.3).

A different aspect of geographical variability is revealed by altitudinal distribution. Differences in the body-tail proportions between mountain and lowland populations were described by Schaefer (1935). Claude (1968) compared Swiss populations of bank voles from Zurich and Göschnerlap, and found an isometric growth of the tail and body length for high mountain populations, contrasting with allometric growth populations inhabiting lower regions. This phenomenon cannot be explained by the effect of physical factors or by a subspecific differentiation. Bank voles living in the mountains are larger than those from lowlands (Claude, 1967; Haitlinger, 1970). According to the ecological interpretation of this fact by Claude $(1967,1970)$, alpine populations have a different age structure; they are predominated by older individuals as their winter mortality is lower in the mountains than in the lowland, and in addition they reach maturity in the next calendar year. The two-step growth of these voles promotes greater body size. A similar situation was observed by Jewell on the Skomer Island, where the reproductive period of voles was short and delayed, and the animals were larger than in England (cit. after Claude, 1967). Other authors argue that the larger size of Scandinavian and high-mountain forms is due to the Bergmann rule (Saint Girons, 1973).

\subsubsection{Subspecific Differentiation}

Ellerman and Morrison-Scott (1951) distinguished 72 forms of $\mathrm{Pa}-$ laearctic Clethrionomys, including 23 subspecies of Clethrionomys glareolus. A taxonomic analysis of subspecies is beyond the scope of this 
paper as it would require some revision; recently there is a tendency to integrate minor groups on the basis of modern craniometry and variability analyses in representative series of material from various parts of the species range. Such a revision on the scale of the entire range has not been carried out so far, and partial analyses have provided a basis for some simplifications of the complex and often controversial division of subspecific forms.

For a long time the differentiation of C. glareolus in the European part of its range was interpreted on the basis of a zoogeographic-phylogenetic concept. According to this concept, in the Pleistocene continental Europe was inhabited by a larger form of Clethrionomys ("nageri" group), which was replaced in the postglacial period by a smaller race from the east. Relicts of the original from were to survive in the high Alps, in western Norway, and on isolated islands off the British coast (Hinton, 1926; Zimmermann, 1950; Matthews, 1952). This concept was not consistent with later findings.

Prychodko (1951) challenged the distinction of the mountain race, C. g. vesanus, described by Hinton from Bavaria. Claude (1970) joined C. $g$. vesanus with C. g. ruttneri in the subspecies C. g. helveticus, on the basis of body and skull measurements, and coloration. He also suggests that large alpine forms can only be an ecological race (Claude, 1967). Steven (1955), who experimentally crossed the form representing the nageri group (British and Norwegian) with the form from England (C. g. britannicus), found no differences in their biology. Corbet (1964) questioned the distinction of the main British form, C. g. britannicus, and included it with C. g. glareolus.

Outlining the problem of taxonomic division of the European forms, it can be stated that the nominative subspecies inhabits the bulk of the continent, while the morphologically distinct subspecies either are geographically isolated (islets, mountains) or inhabit suboptimal habitats at the margin of their geographic range.

Unquestionable subspecies now include the races described from the British Isles (Steven, 1955; Corbet, 1964):

C. g. caesarius - from Jersey (Channel Islands),

C. g. skomerensis - from the Isle of Skomer (Wales),

C. g. alstoni - from the Isle of Mull (Inner Hebrides),

C. g. erica - from the Isle of Rassay (Inner Hebrides). They are distinguished by their body and skull size (all are larger than British forms) and by $\mathrm{M}^{3}$ structure. C. g. skomerensis is differently colored (lighter, with cream-colored belly in winter). According to present views on their origin, they are not relicts but were casually introduced, probably by man, and then geographically isolated (Corbet, 1964). 
According to karyotaxonomic criteria, forms living in southern parts of the species range: C. g. garganicus from Italy and C. g. istericus from the southern Carpathians, can be considered as distinct (Král, 1972; Král et al., 1972), though according to Rossolimo (1964) there are no morphological differences in the body and skull structure between the latter and C. g. glareolus. Probably C. g. ponticus from Asia Minor or C. g. curcio from southern Italy are distinct forms, but this separation requires some conclusive evidence. A detailed analysis of alpine forms carried out by Gruber and Kahman (1968) indicates that it is necessary to fuse into larger groups the units distinguished so far, this being a conclusion from the statistical analysis of biometric data. The ultimate subdivision of the species Clethrionomys glareolus living in central Europe (the Alps, Balkan) and, in particular, over vast areas of the eastern range of this species, has to be based on reliable material analysis. A supplementary list of the subspecies described so far was provided by Corbet (1978).

\subsubsection{Characteristics of Bank Voles Living in Poland}

Two bank vole populations from Poland have detailed biomorphological descriptions: one in Białowieża (Wasilewski, 1952; Kubik, 1965) and another one in the Wrockaw region (Haitlinger, 1965). To characterize these two populations, the basic body and skull measurements are given in Table 2.1.

Both these characteristics are based on the mechanism and differentiation of growth rate of particular parameters of skull in relation to seasonal events occurring in these populations. Wasilewski (1952), using the least squares method for the craniometric analysis, distinguished 12 "types" of skull structure in the Białowieża population that differ in the proportions of linear dimensions. This method of analysis, however, does not allow far reaching taxonomic conclusions because the range of the variability of the Białowieża population covers also other forms of European Clethrionomys glareolus.

A comparison of the parameters of skull growth between the Białowieża and Wrocław populations reveals few noticeable differences. According to Haitlinger (1965), the specific features of the Wrocław population include the length of nasal bones, saggital suture, and palatial length. In both populations the growth rate of the spring generation was higher than autumnal generation (Kubik, 1965; Haitlinger, 1965). Sexual dimorphism in the bank vole occurs during the breeding season; it concerns the body weight, which is higher at the end of winter for males and in spring for females. Craniometric differences between sexes are 
difficult to prove (Haitlinger, 1965). The body weight also undergoes seasonal changes. It is lower in winter for all age classes by about $6 \mathrm{~g}$ as compared with the maximum value reached in summer. The body

Table 2.1.

Morphological characteristics of Clethrionomys glareolus from Poland.

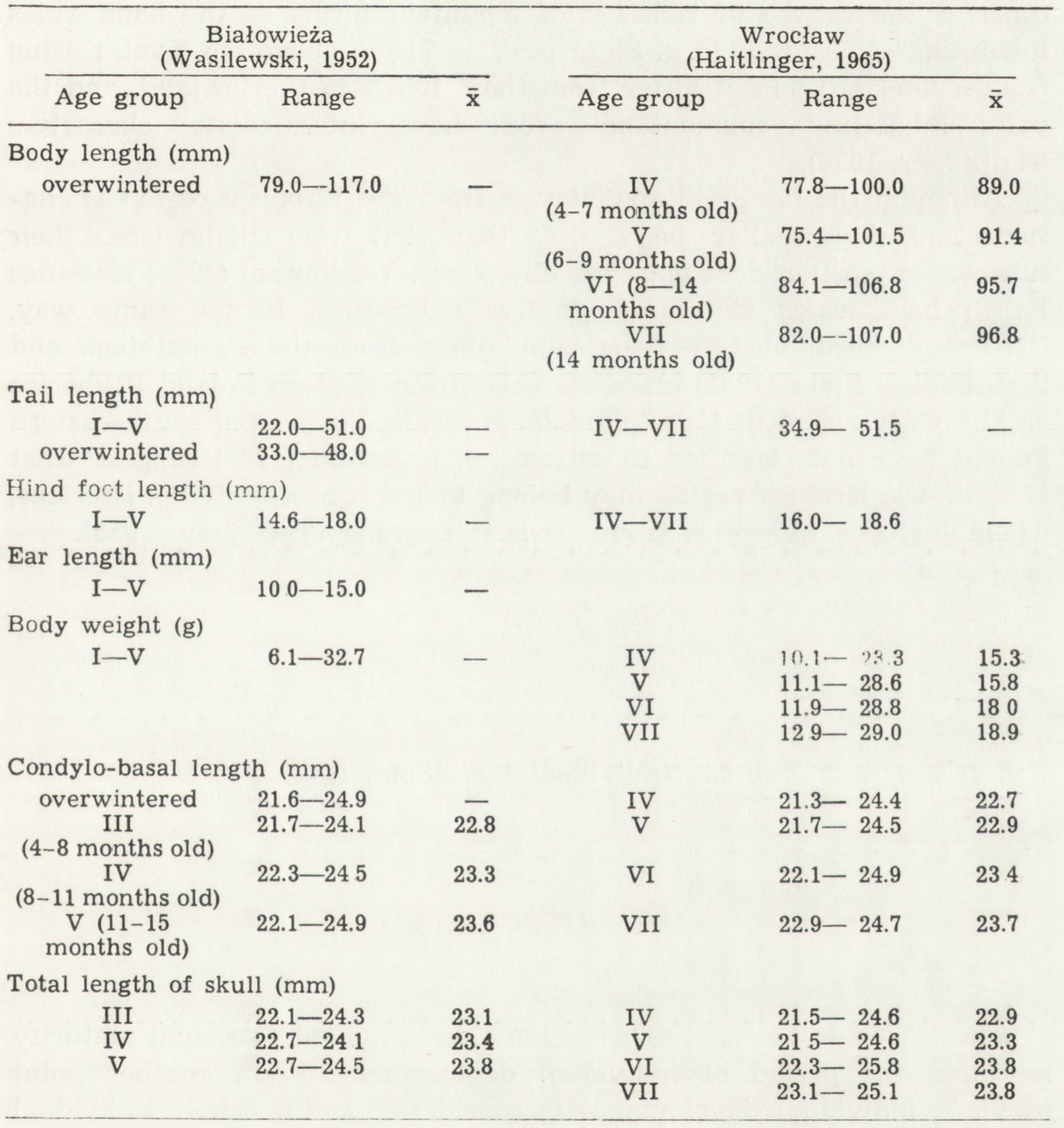

weight increases in March and it attains maximum values in June and July (Haitlinger, 1965).

As only few populations from Poland were morphologically studied, it is not possible to estimate the range of variability of different forms and to characterize trends in body and skull sizes over the country. 
Poland, however, lies in the centre of the bank vole range, is small relative to the range of this species, and so is not likely to be a good place to follow such trends. Nevertheless, it has been found that bank voles from mountain populations in the Karkonosze Mts. are larger than those from Wrocław and submontane regions. These are, however, allometric relationships. The interpretation of this phenomenon should consider the degree of isolation of mountain forms as the bank voles inhabiting some peaks (e. g. Slęża peak - $718 \mathrm{~m}$ above sea level, raising from a lowland) do not differ from those living in the lowland, and the voles inhabiting submontane areas have intermediate characters (Haitlinger, 1970).

Although the bank vole population from the Wrocław region is characterized by smaller body sizes than that from Białowieża, their subspecific position does not rises objections. Wasilewski (1952) classifies Polish bank voles to the nominative subspecies. In the same way, Haitlinger (1970) classifies the populations from the Carpathians and the Sudetes. Stein (1931) classifies voles from western Poland (Rybocice on the Oder river) to C. g. glareolus as well. Voles from south-eastern Poland were not classified to subspecies. Kowalski (1964) suggests that voles of the Krakow region may belong to the subspecies C. g. istericus, which includes the voles from western Ukraine (Tatarinov, 1956).

\subsection{Individual Development}

\section{Marek GĘBCZYŃSKI}

The period from onset of embryonic development to sexual maturity is called the period of individual development. From another point of view, individual development is considered as the whole individual life span, that is, it also includes the phase of maturity and aging. However, the sequence of changes in shape and functioning is most rapid until sexual maturity, therefore this period of life is of particular interest. In the bank vole it covers about 60 days, including 17-22 days of the embryonic (prenatal) development and then the postnatal development. 